Supplement of Biogeosciences, 11, 7179-7192, 2014

http://www.biogeosciences.net/11/7179/2014/

doi:10.5194/bg-11-7179-2014-supplement

(C) Author(s) 2014. CC Attribution 3.0 License.

(c) (i)

Supplement of

\title{
Inorganic carbon fluxes across the vadose zone of planted and unplanted soil mesocosms
}

E. M. Thaysen et al.

Correspondence to: E. M. Thaysen (eikethaysen@idaea.csic.es) 


\section{Supplementary Information}

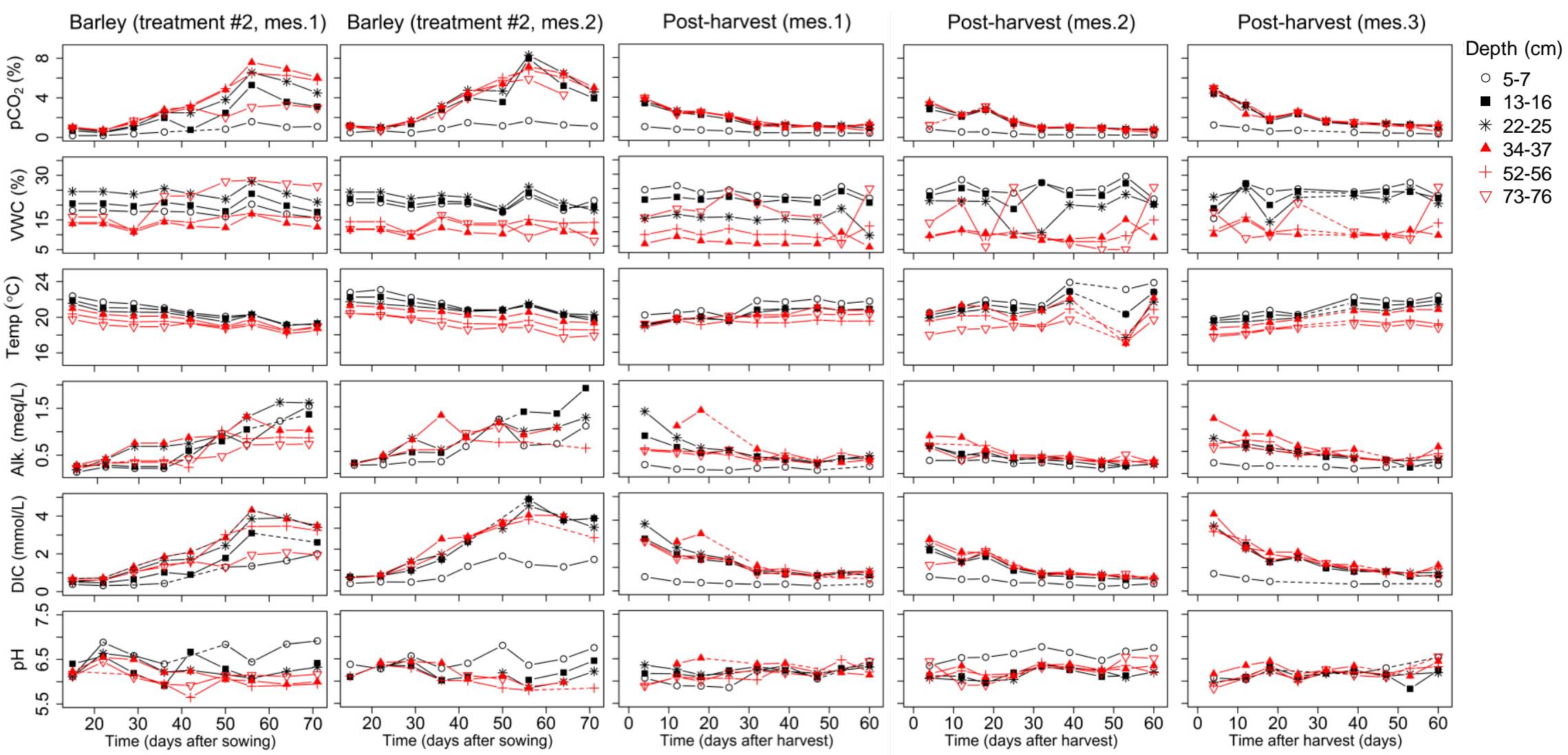

Fig. S1. Time course of $\mathrm{pCO}_{2}$, volumetric water content (VWC), temperature, alkalinity (Alk.), DIC and pH on measurement days throughout depth during barley growth (treatment \#2) and after harvest. Measurements at 45 and $63 \mathrm{~cm}$ depth were excluded for clarification of the figure but followed the same trends as measurements at $13-56 \mathrm{~cm}$. Note the different $\mathrm{x}$ axis scale for the subfigures. 


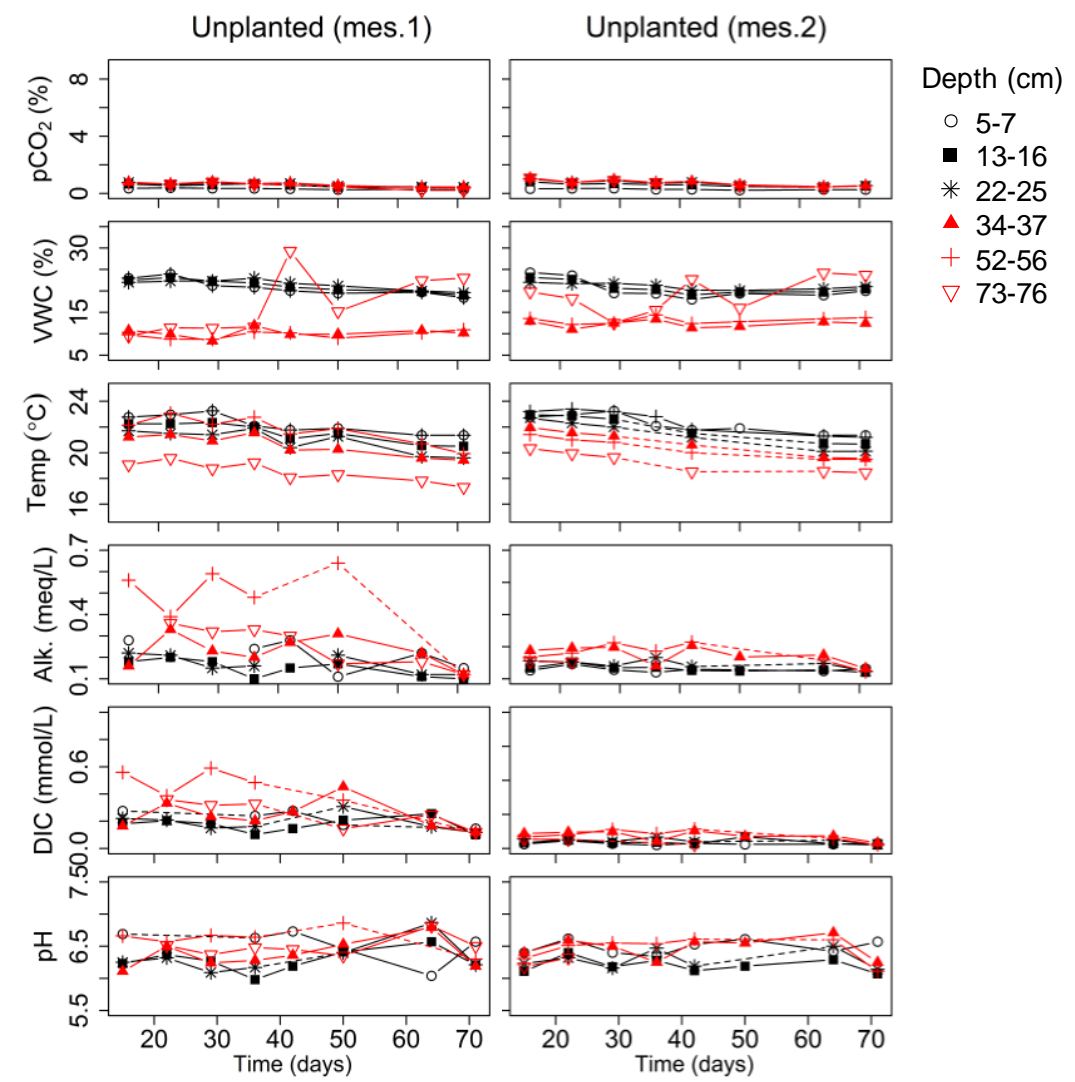

Fig. S1 (continued). Time course of $\mathrm{pCO}_{2}$, volumetric water content (VWC), temperature, alkalinity (Alk.), DIC and pH on measurement days throughout depth in unplanted soil. Measurements at 45 and $63 \mathrm{~cm}$ depth were excluded for clarification of the figure but followed the same trends as measurements at $13-56 \mathrm{~cm}$. 

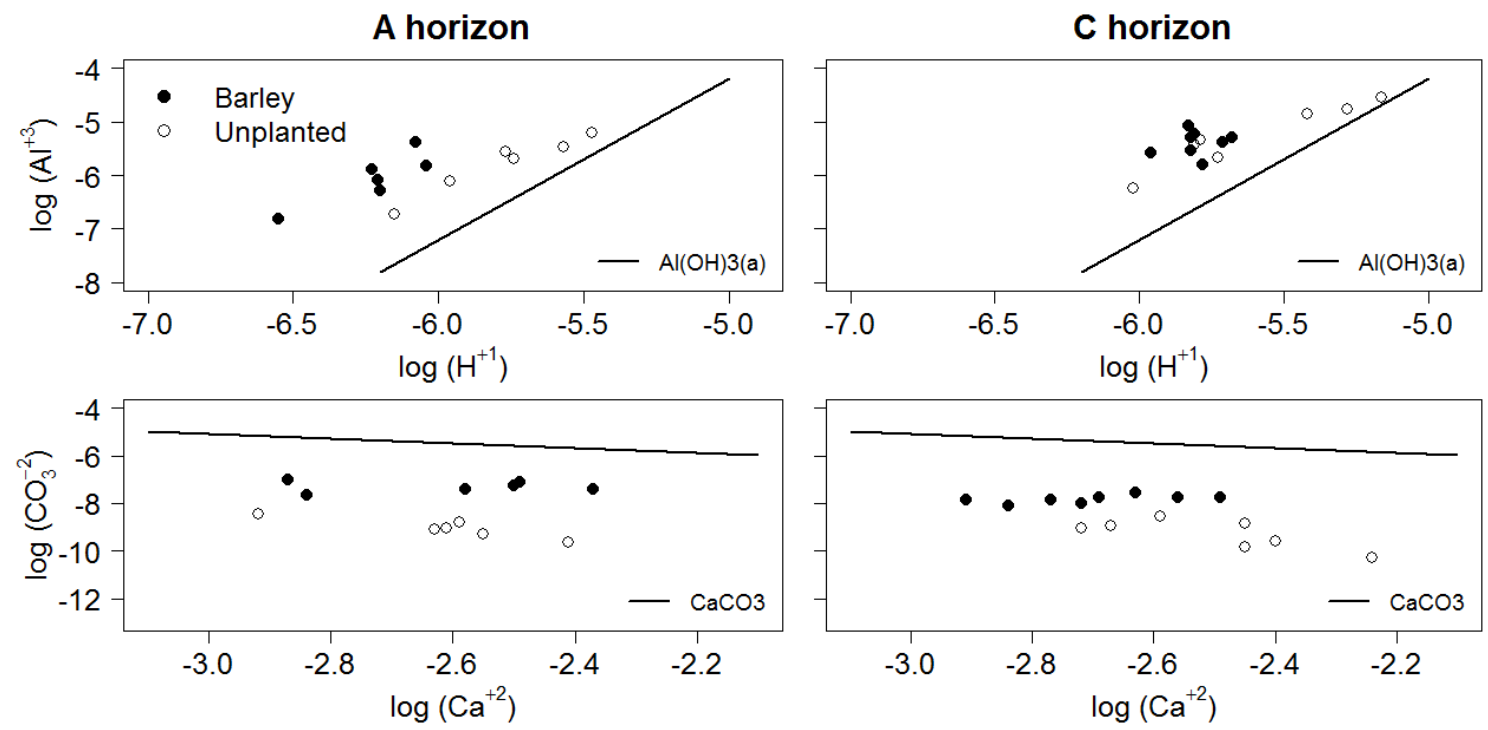

Fig. S2: Log activities of $\mathrm{Al}^{3+}$ vs. $\mathrm{H}^{+}$as compared to the equilibrium line for $\mathrm{Al}(\mathrm{OH})_{3(\mathrm{a})}$ and $\log$ activities of $\mathrm{CO}_{3}{ }^{2-}$ vs. $\mathrm{Ca}^{2+}$ as compared to the equilibrium line for $\mathrm{CaCO}_{3}$ of pore water in $\mathrm{A}$ and $\mathrm{C}$ horizons on day 71 (series 2 mesocosms only). Samples were analyzed by ICP-MS (Elan6100DRC, Perkin Elmer, CAN), and concentrations were corrected for dilution by the acid added during a previous alkalinity titration. Saturation indices of different minerals in the mesocosms were calculated with PHREEQC software (Parkhurst and Appelo, 2011). Concentrations of the major anions $\mathrm{NO}_{3}{ }^{-}$and $\mathrm{SO}_{4}{ }^{2-}$ were set to 62 and $96 \mathrm{mg} \mathrm{L}^{-1}$, respectively, as given by the Hoagland solution composition (Hoagland and Amon, 1950). Solutions were charged balanced by adding either $\mathrm{Li}^{+}$or $\mathrm{Cl}^{-}$until electro neutrality.

The pore water was supersaturated for amorphous aluminum hydroxide, $\mathrm{Al}(\mathrm{OH})_{3(\mathrm{a})}$, and this indicates the possible precipitation of a gibbsite-type mineral. The soil solutions were subsaturated for calcite, $\mathrm{CaCO}_{3}$, indicating the possible dissolution of lime particles added to the field site. The relations between measurement points and the equilibrium lines were less parallel in the $\mathrm{C}$ horizon, indicating less control of either aluminum hydroxide or calcite in the subsoil. Activities of $\mathrm{H}^{+}$were generally lower in the pore water samples from planted soil than in unplanted soil, while activities of $\mathrm{CO}_{3}{ }^{2-}$ were slightly elevated. 
Nutrient uptake
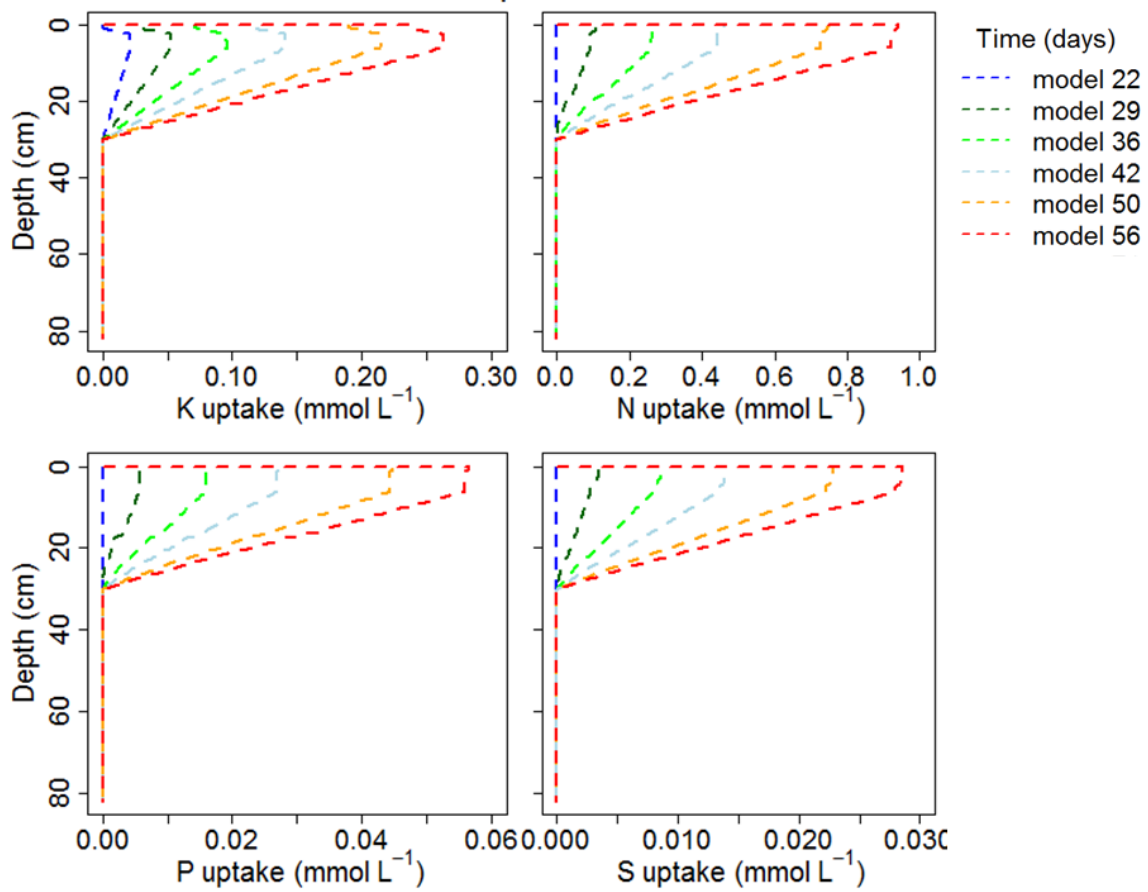

3

Fig. S3: Simulated nutrient uptake rates of remaining nutrients.

5

6

7 


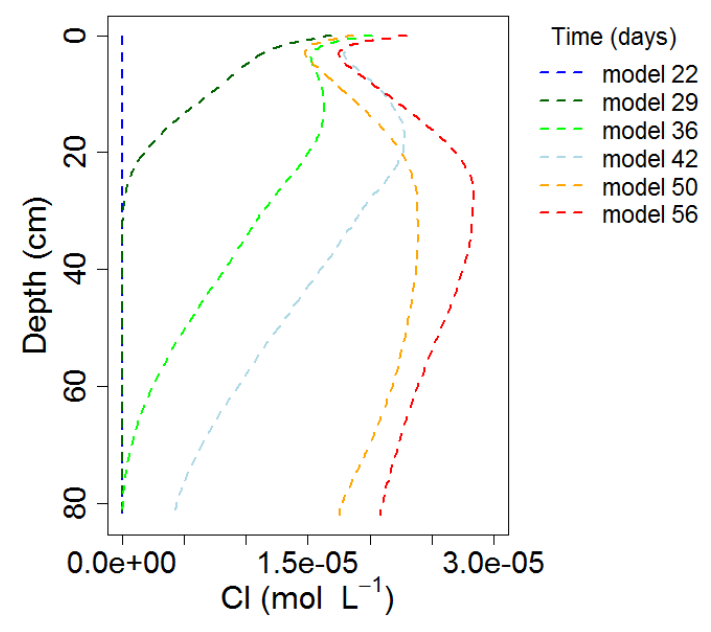

2 Fig. S4: Simulated movement of chloride tracer applied at a concentration of $0.92 * 10^{-5}$ moles $3 \mathrm{~L}^{-1}$. Combined action of evaporation and transpiration increased tracer concentration $\sim 3$ times. 4 Evapotranspiration caused a peak in the tracer concentration in the $\mathrm{C}$ horizon. Evaporation 5 causes steep increases in the tracer concentration at the very top of the mesocosm.

6 

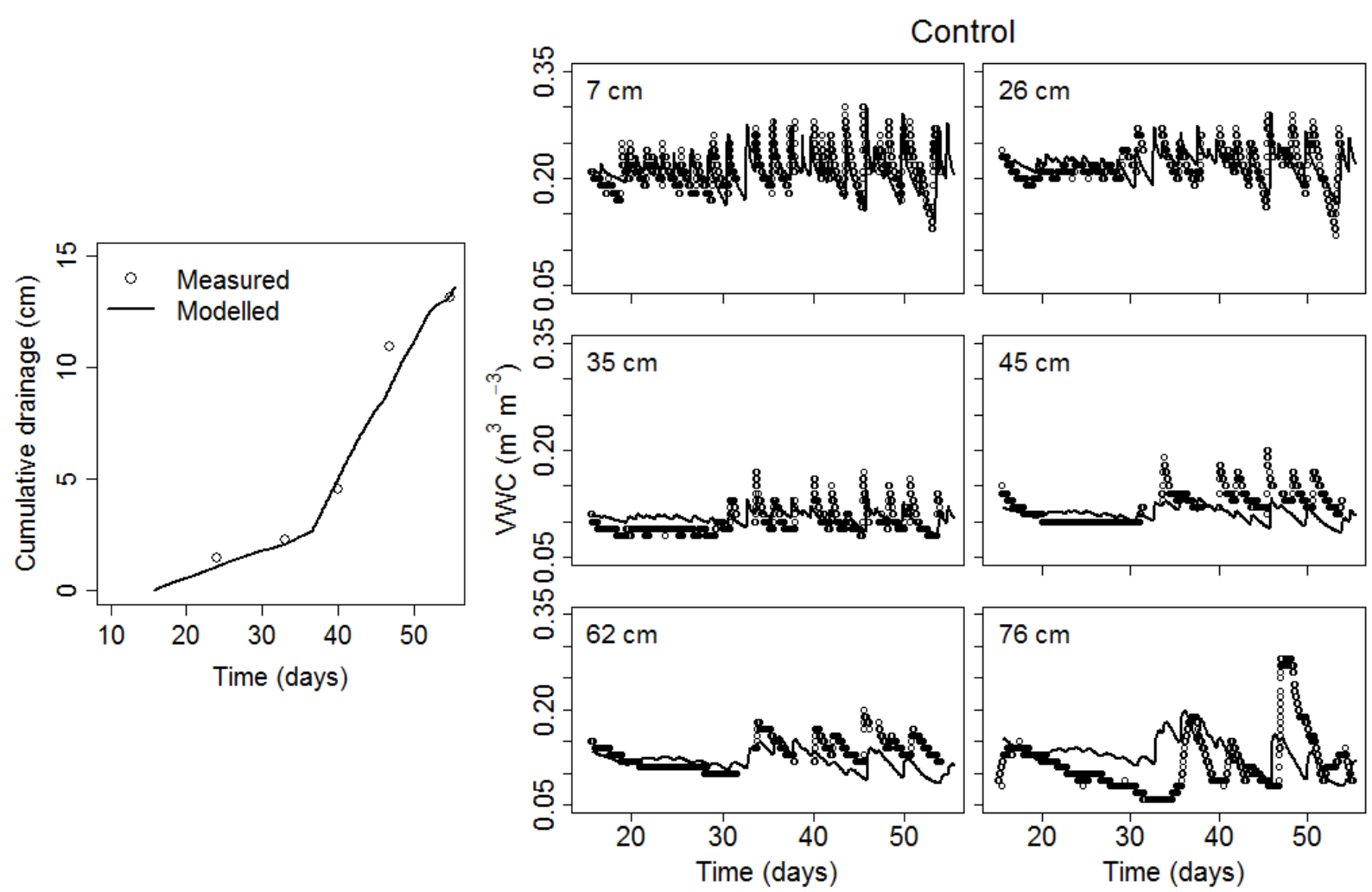

2 Fig. S5: Measured and modeled cumulative drainage and volumetric water content (VWC) in 3 barley mesocosm 5 .

4 


\section{Text S1: Calculation of theoretical diffusion coefficients}

2 Theoretical bulk diffusion diffusivities, D, were calculated using the empiral formulas of

3 Rogers and Nielson (1991) and Andersen (2000) (Eq. 1-3).

$4 \quad \mathrm{D}=\mathrm{D}_{\mathrm{e}} \beta$

$5 \quad \mathrm{D}_{\mathrm{e}}=\mathrm{D}_{0} \varepsilon \exp \left(-6 \mathrm{~m} \varepsilon-6 \mathrm{~m}^{14 \varepsilon}\right)$

$6 \beta=\varepsilon_{\mathrm{a}}+\mathrm{L} \varepsilon_{\mathrm{w}}+\mathrm{K} \rho \mathrm{b}$

7 where $D_{e}$ is the effective diffusion coefficient $\left(\mathrm{m}^{2} \mathrm{~s}^{-1}\right), D_{0}$ is the diffusion coefficient in air $8 \quad\left(\mathrm{~m}^{2} \mathrm{~s}^{-1}\right), \varepsilon$ is the total porosity $\left(\mathrm{m}^{3} \mathrm{~m}^{-3}\right), \varepsilon_{a}$ is the air-filled porosity $\left(\mathrm{m}^{3} \mathrm{~m}^{-3}\right), \varepsilon_{w}$ is the water-

9 filled porosity $\left(\mathrm{m}^{3} \mathrm{~m}^{-3}\right), m$ is the water saturation $\left(\varepsilon_{w} / \varepsilon\right)\left(\mathrm{m}^{3} \mathrm{~m}^{-3}\right), L$ is the Ostwald coefficient 10 (equals approx. 0.36 at $10^{\circ} \mathrm{C}$ and 0.23 at $25^{\circ} \mathrm{C}$ (Clever, 1979)) and $K$ is the radon surface 11 sorption coefficient $\left(\mathrm{kg} \mathrm{m}^{-3}\right)$ (Rogers and Nielson, 1991), and $\rho b$ is the soil bulk density ( $\mathrm{kg}$ $\left.12 \mathrm{~m}^{-3}\right)$.

13 In the calculations $\varepsilon_{w}$ was set to 0.2 and $0.1\left(\mathrm{~m}^{3} \mathrm{~m}^{-3}\right)$ for the A and $\mathrm{C}$ horizon, respectively, $\rho b$ 14 was 1.45 and $1.53 \mathrm{~kg} \mathrm{~m}^{-3}$ for the $\mathrm{A}$ and $\mathrm{C}$ horizon, respectively, and $K$ was assumed to be $0 . L$ 15 was set to 0.26 . Total porosities of the $\mathrm{A}$ and $\mathrm{C}$ horizon were 0.45 and 0.43 , respectively. 
1 Table S1: Parameters used in the modeling of soil $\mathrm{CO}_{2}$ fluxes. DW= dry weight.

$\left.\begin{array}{cccc}\hline \text { Symbol } & \text { Meaning } & \text { Value } & \text { Calculation/Source } \\ \hline \boldsymbol{R}_{\text {init }} & \begin{array}{c}\text { Initial root } \\ \text { mass }\end{array} & 2.0 \mathrm{~g} \mathrm{DW} & \begin{array}{c}\text { Calculated from the measured root mass } \\ \text { (Table 3) assuming linear root growth }\end{array} \\ \boldsymbol{r} & \begin{array}{c}\text { Root growth } \\ \text { rate }\end{array} & 2.4{ }^{*} 10^{-6} \mathrm{~g} \mathrm{~s}^{-1} & \begin{array}{c}\text { Calculated from the measured root mass } 65.5 \\ \text { days after germination (Table 3) and assuming } \\ \text { linear root growth }\end{array} \\ \boldsymbol{R M I} & \begin{array}{c}\text { Root mass } \\ \text { index }\end{array} & & \text { Calculated by } R_{\text {init }}+r^{*} \text { time) }\end{array}\right)$




\section{References}

2 Clever, H. L.: Solubility data series. Krypton, xenon and radon-gas solubilities, Pergamon

3 Press, 1979.

4 Dunlop, J.: The kinetic uptake of calcium by roots, Planta, 112, 159-167, 1973.

5 Hoagland, D. R., and Amon, D. I.: The water-culture method for growing plants without soil,

6 College of Agriculture, University of California, Berkley, 1950.

7 Marschner, H.: Mineral nutrition of higher plants, Second Edition ed., Academic Press

8 Limited, London, 1995.

9 Nielsen, N. E.: Forløbet af rodudvikling, næringsstofoptagelse of stofproduktion hos byg, 10 dyrket på frugtbar morænelerjord, Royal Veterenary and Agricultural University, 11 Copenhagen, DK, 1982.

12 Nissen, P.: Multiphasic uptake in plants II. Mineral cations, chloride, and boric acid, Physiol 13 Plantarum, 29, 298-354, 1973a.

14 Nissen, P.: Multiphasic uptake in plants I. Phosphate and sulphate, Plant Physiol, 28, 304-316, $151973 b$.

16 Parkhurst, D., and Appelo, C. A. J.: PHREEQC (Version 3)- A computer program for 17 speciation, batch-reaction, one-dimensional transport, and inverse geochemical calculations, 18 U.S. Geological Survey, Water Resources Division, Denver, Colorado, USA, 2011.

19 Rao, K. P., and Rains, D. W.: Nitrate absorption by barley, Plant Physiol, 57, 55-58, 1976.

20 Rogers, V. C., and Nielson, K. K.: Correlations for predicting air permeabilities and ${ }^{222} \mathrm{Rn}$ 21 diffusion coefficients og soils, Health Phys, 61, 225-230, 1991. 